\title{
Modernizing medical school admission processes: a European perspective
}

This article was published in the following Dove Press journal:

Advances in Medical Education and Practice

17 October 2016

Number of times this article has been viewed

\section{Adam K Karlsson \\ Karl O Elmqvist}

Faculty of Medicine, Imperial College London, London, UK
Correspondence: Adam K Karlsson

Level 2, Faculty Building, South Kensington Campus, Imperial College London, London SW7 2AZ, UK

Tel +447446950989

Email adam.karlsson12@imperial.ac.uk

\section{Dear editor}

We read with keen interest the commentary by Eltorai and Daniels ${ }^{1}$ wherein they suggested a streamlining of the current US medical school admission process, through the development of a common application system called the National Medical School Matching Program (NMSMP). This, the authors argue, would not only improve the efficiency by centralizing the application process, reducing the number of futile interviews and the need for superfluous documentation, but also significantly reduce the costs to both the applicant and the medical schools.

We agree with the authors of the commentary, that the current US medical school admission process appears unnecessarily arduous and costly for all parties, and that an overhaul such as the one described would be hugely beneficial. Specifically, we note the huge cost that an applicant is likely to incur, estimated at $\$ 7,655.50$, as especially problematic, as it may exclude applications from those of poorer backgrounds, worsening their accessibility to the profession. Moreover, the lack of a centralized system, such as University and Colleges Admissions Service (UCAS) ${ }^{2}$ used in the UK, places an unnecessary burden on the applicants, and increases the paperwork for all involved.

The proposed solution would bring the application process more in the line with the current UK system, for which we wish to share our experience and views. Additionally, we hope that by comparing and contrasting with another European country also recognized for its high standard of medical education - Sweden - that this may be informative, and further strengthen the case for change in the US.

Unlike in the US, the UK applicant would submit her application, consisting of a personal statement, academic reference, educational history, aptitude test scores (UKCAT or BMAT) to the centralized application system, UCAS, along with a choice of maximum four, from the 33 medical schools. ${ }^{3}$ Promising applicants are interviewed, and those successful are given conditional offers (guarantees of acceptance if specified grades are achieved). Those with multiple offers rank one as their "firm" offer and another as their "insurance" offer, with the latter being withdrawn if the conditions of the former are met.

We would argue that the UK application system is superior, primarily based on the lower costs for the individual applicant, and the existence of a centralized application platform, limiting the number of medical course applications to four. The only costs for a UK applicant are a UCAS application fee (£24), ${ }^{4}$ aptitude tests fees (UKCAT 
$£ 65,{ }^{5}$ BMAT $£ 45^{6}$ ), optional preparatory courses (approximately $£ 280^{7}$ ), and any travel and accommodation expenses associated with interviews, bringing the total to a negligible sum in view of the US figure. One could, however, argue that the comparatively low number of applications allowed, is overly restrictive for the individual applicant, and that it may deter some from applying to their dream school out of fear of wasting an application on a highly competitive institution. On balance, we maintain that this system forces students to be more focused in their application, without adversely affecting their chances of being admitted, given that the ratio of applicants to places should, in theory, remain unchanged. Furthermore, this reduces the administrative load on medical schools.

Interestingly, the application system in Sweden differs significantly from those described earlier. In Sweden, applicants rank medical schools in order of preference. They apply using a centralized system, through which there are three admission routes, ${ }^{8}$ each constituting approximately a third of the total intake:

(1) Academic - high school grades.

(2) Swedish Scholastic Aptitude Test (SweSAT).

(3) University specific - personal letters, aptitude tests, and interviews.

Up until the recent introduction of the university-specific admission component, ${ }^{9}$ the Swedish system was unidimensional, exclusively assessing the academic prowess of applicants. However, the third route is similar to the UK system, taking a more holistic approach, by determining not only the applicant's predicted ability to progress through a demanding medical degree, but also one's suitability as a medical professional. While the minimal cost to the applicant (only $£ 40^{10}$ for those wishing to go through the SweSAT route) is strongly appreciated by the authors, the increased efficiency of a largely academic-based application system does not justify the lack of a global view of an applicant's qualities.

In conclusion, after reviewing two European medical school application processes, a move by the US toward a system more aligned with the one in place in the UK, such as the NMSMP, would indeed increase the efficiency and reduce the costs to both applicants and medical schools.

\section{Disclosure}

The authors report no conflicts of interest in this communication.

\section{References}

1. Eltorai AE, Daniels AH. National Medical School Matching Program: optimizing outcomes. Adv Med Educ Pract. 2016;7:371-373.

2. The Universities and Colleges Admissions Service. Available from: https://www.ucas.com. Accessed August 25, 2016.

3. British Medical Association. Applying to medical school. Available from: https://www.bma.org.uk/advice/career/studying-medicine/howto-become-a-doctor/applying-to-medical-school. Accessed August 25, 2016.

4. The Universities and Colleges Admissions Service. Filling in your UCAS Undergraduate application. Available from: https://www.ucas. $\mathrm{com} /$ ucas/undergraduate/apply-and-track/filling-your-ucas-undergraduate-application. Accessed August 25, 2016.

5. UK Clinical Aptitude Test. Registration and Booking: UKCAT. Available from: http://www.ukcat.ac.uk/registration. Accessed August 25, 2016.

6. Admissions Testing Service. Dates and costs. Available from: http:// www.admissionstestingservice.org/for-test-takers/bmat/dates-andcosts/. Accessed August 25, 2016

7. Kaplan Test Prep. BMAT Preparation: BMAT Courses and Tutoring. Available from: http://www.kaptest.co.uk/courses/uk-university/bmat/ bmat-preparation. Accessed August 25, 2016.

8. Karolinska Institutet. Urval. Available from: http://ki.se/utbildning/ urval. Accessed August 25, 2016.

9. Nilsson G. KI:s alternativa urval till läkarprogrammet utvecklas fortlöpande. Available from: http://www.lakartidningen.se/Functions/ OldArticleView.aspx?articleId=18441. Accessed August 25, 2016.

10. Högskoleprovet. Ny avgift för Högskoleprovet. Available from: http:// www.högskoleprovet2016.se/ny-avgift-for-hogskoleprovet/. Accessed August 25, 2016. 


\section{Authors' reply \\ Adam EM Eltorai \\ Wesley M Durand \\ Alan H Daniels}

Warren Alpert Medical School, Brown University, Providence, RI, USA

Correspondence: Adam EM Eltorai

Warren Alpert Medical School, Brown University, 222 Richmond St., Box G-9999, Providence, RI 02903, USA

\section{Dear editor}

We appreciate the commentary provided by Karlsson and Elmqvist in comparing a potential National Medical School Matching Program (NMSMP) to extant medical school application systems in the UK and Sweden. Key learnings from these processes provide a context with which to refine parameters for a NMSMP.

There appear to be four primary factors leading to increased efficiency and decreased cost in the UK system: 1) reduced primary application costs, 2) reduced costs associated with standardized testing, 3) lack of secondary, schoolspecific applications, and 4) a maximal limit on the number of applications per individual. Addressing the former three factors, it is yet to be determined whether or not implementation of a NMSMP in the US would result in reduced primary application and standardized testing costs (factors 1 and 2), and our prior articulation of a NMSMP involved an elimination of secondary applications (factor 3). ${ }^{1}$

Placement of an upper limit on application number (factor 4) deserves careful consideration, as it is arguably the element most responsible for increased efficiency in the UK system. In comparison to the UK maximum of four applications, US applicants submitted an average of 14.8 applications in 2014. However, there are significantly more individual medical schools in the US than in the UK (145 vs. 33, including only allopathic MD-granting US institutions). If the upper limit for applications in the US was scaled proportionally to the higher number of schools, the limit would be placed at 17.6 (or 4/33 [12.1\%] of institutions). Implementation of a US limit lower than this number would be pragmatic in reducing the total number of applications, but would restrict applicant choices to a greater relative degree than in the UK.

For comparison, the current US National Resident Matching Program (NRMP) does not impose an upper limit for applications (applications are submitted initially through the Electronic Residency Application System [ERAS]). In 2014,
ERAS applicants submitted an average of 27.9 applications per person. ${ }^{2}$ While there are many relevant differences between the NRMP and the proposed NMSMP, one similarity is the lack of secondary applications/fees. It is likely that the financial and time requirements associated with medical school secondary applications provide downward pressure on the number of applications per US applicant. Release of such pressure with NMSMP adoption could lead to an increase in the number of primary applications per applicant (potentially to ERAS levels). Such a trend would increase costs for students associated with primary applications and increase the application review burden for medical school admissions offices - this would serve to partially offset efficiency gained through elimination of secondary applications. As a result, if a NMSMP is implemented, administrators should monitor for this trend and be prepared to consider limiting the maximum number of applications.

The Swedish system provides interesting contrast to a NMSMP. While utilizing a centralized application platform, there exist several, highly differentiated pathways for Swedish applications. We concur with Karlsson and Elmqvist in favoring a holistic approach to evaluation over permitting support of an application solely based on aptitude test scores. Of note is that the average US medical school applicant in 2015 was 23-24 years old, whereas Swedish and UK medical schools accept students immediately following secondary education. ${ }^{3}$ It is therefore reasonable for US medical schools to consider a wide breadth of factors when evaluating potential students, given greater divergence of experience in the postsecondary years. Commensurate with a more aged applicant population, adoption of a NMSMP would also allow for "couples matching" (similar to the current NRMP system). ${ }^{4}$ This function may be increasingly vital as the average US medical student applicant age continues to rise.

To this point, comparison to the NRMP strongly supports NMSMP adoption. The Match algorithm incentivizes ranking of programs based on "true preference" strategy, ensuring that students will be placed in their highest ranked available program. ${ }^{5}$ This process has been successful in alleviating past nonoptimality in the internship/residency application system. ${ }^{6}$ Such success is attested by the explicit statutory exemption of the NRMP from antitrust litigation - this legislation finds the Match program to be "highly efficient, pro-competitive, and long-standing", providing an important legal precedent for NMSMP creation. ${ }^{7}$

In summary, comparison of a NMSMP to UK and Swedish medical school application systems allows for refinement of proposed approach. Most notably, the UK 
experience suggests that an upper limit on applications per applicant may be required to realize the full efficiency potential of a US NMSMP. However, the efficiency benefits of such a proposal should be carefully weighed against restrictions of choice. The most direct beneficiaries of increased application efficiency will be applicants and admissions offices and if, on balance, these stakeholders would prefer greater freedom over increased efficiency, their perspectives should be heavily weighted before imposing such a limit.

\section{Disclosure}

The authors report no conflicts of interest in this communication.

\section{References}

1. Eltorai AE, Daniels AH. National Medical School Matching Program: optimizing outcomes. Adv Med Educ Pract. 2016;7:371-373.

2. Electronic Residency Application Service. ERAS Statistics; 2016. Available from: https://www.aamc.org/services/eras/stats/359278/stats.html. Accessed September 27, 2016.

3. American Association of Medical Colleges. Applicants and Matriculants Data; 2016. Available from: https://www.aamc.org/download/321468/ data/factstablea6.pdf. Accessed September 27, 2016.

4. National Resident Matching Program. Participating as a Couple;2016.Available from: http://www.nrmp.org/match-process/couples-in-the-match/. Accessed September 27, 2016.

5. Purushottam A, Nagarkar, Jeffrey E. Fixing the "match": how to play the game. J Grad Med Educ. 2012;4(2):142-147.

6. Roth AE. The origins, history, and design of the resident match. JAMA. 2003;289(7):909-912.

7. United States Congress. "Public Law. 108-218, title II, §207, Apr. 10, 2004, 118 Stat. 611" (n.d.).

Dove Medical Press encourages responsible, free and frank academic debate. The content of the Advances in Medical Education and Practice 'letters to the editor' section does not necessarily represent the views of Dove Medical Press, its officers, agents, employees, related entities or the Advances in Medical Education and Practice editors. While all reasonable steps have been taken to confirm the content of each letter, Dove Medical Press accepts no liability in respect of the content of any letter, nor is it responsible for the content and accuracy of any letter to the editor.

\section{Publish your work in this journal}

Advances in Medical Education and Practice is an international, peerreviewed, open access journal that aims to present and publish research on Medical Education covering medical, dental, nursing and allied health care professional education. The journal covers undergraduate education, postgraduate training and continuing medical education including emerging trends and innovative models linking education, research, and health care services. The manuscript management system is completely online and includes a very quick and fair peer-review system. Visit http://www.dovepress.com/testimonials.php to read real quotes from published authors. 